\title{
CARCINOMA OF THE BRONCHUS
}

\author{
A REPORT ON THE FIRST FIVE YEARS' WORK OF THE JOINT \\ CONSULTATION CLINIC FOR NEOPLASTIC DISEASES OF \\ THE BROMPTON HOSPITAL AND THE ROYAL \\ CANCER HOSPITAL
}

BY

\begin{abstract}
W. D. W. BROOKS, M. DAVIDSON, C. PRICE THOMAS, K. ROBSON, AND D. W. SMITHERS
\end{abstract}

The Joint Consultation Clinic for Neoplastic Diseases was started as a reference clinic to which patients suspected of having carcinoma of the bronchus could be referred from both hospitals for consideration of treatment by radiotherapy and, later, chemotherapy as well. It was decided that a careful record and follow-up should be kept of every patient seen-whether treated or not-and an effort made to assess the value of these methods of treatment alone or in combination with surgery. The work was begun, in May, 1944, by two of us (M. D. and D. W. S.) with the late Mr. J. E. H. Roberts, as a co-operative investigation between the two hospitals, and has continued, with a physician, a surgeon, and a radiotherapist in consultation, each week since then.

The patients referred to the clinic inevitably form a selected group. For example, the Brompton Hospital records show that approximately 440 patients diagnosed as having a bronchial carcinoma and seen at the Brompton Hospital between 1944 and 1948 were not referred to the clinic. Patients thought suitable for surgery and on whom an operation was performed were seldom seen unless the operation was known or thought to be incomplete, or the patient developed a recurrence. Again, some patients were evidently so ill when first seen that it was thought undesirable to refer them to the clinic. The selection of cases thus resulting has proved to be the main handicap in the clinic's attempt to assess the results of treatment. It should be possible to obtain a more nearly complete picture in the future, since permission has now been given to the clinic to scrutinize the records of all cases of carcinoma of the bronchus occurring in the practice of both hospitals. Another important difficulty has been that most of the patients have died at home so that a post-mortem examination was not made. A high post-mortem examination rate is very desirable in an investigation of this kind.

The whole group of cases has been reviewed for this report, every record being examined anew and all doubtful cases submitted to a further consultation by all members of the clinic. Every patient surviving one year or more from the first time seen has been reviewed in even greater detail, including re-examination of the radiographs and, where available, histological sections. Cases of bronchial carcinoma are throughout divided into those with and those without histological confirmation of the diagnosis so that distinctions may be made. Those cases in which the diagnosis 
of bronchial carcinoma has been rejected on grounds of inadequate evidence are included in a special group, so that the selection made within the clinic's material at least is clear.

Although a majority of patients found to be suitable for operation were not sent to the clinic, we have still considered the possibilities of surgery in each case, and ten were eventually treated by surgery alone. Seven patients were treated by $x$ rays post-operatively when it was known that enlarged nodes remained after operation or when the risk of recurrence in the mediastinal nodes was thought to be high. One patient had a pneumonectomy following irradiation, and was found to have a focus of residual squamous-cell carcinoma embedded in a mass of fibrous tissue; this patient was still alive and well seven months later. Another patient (seen in 1949 and is not included in this report) who also had pre-operative irradiation was found on examination of the lung to have no sign of residual tumour where previously there had been a large mass of oat-cell carcinoma. Four patients who refused thoracotomy received a radical course of $x$-ray therapy.

In the first five years, from May, 1944, to April, 1949, a total of 667 patients was seen. The number seen by the end of 1949 was 762 . This report deals with the 624 patients seen in the years 1944 to 1948 inclusive, so that the results of treatment could be assessed for at least one year in all cases (Table I). The patients are grouped by diagnosis in Tables II, III, and IV.

TABLE I

Total Number of Patients Seen at the Clinic

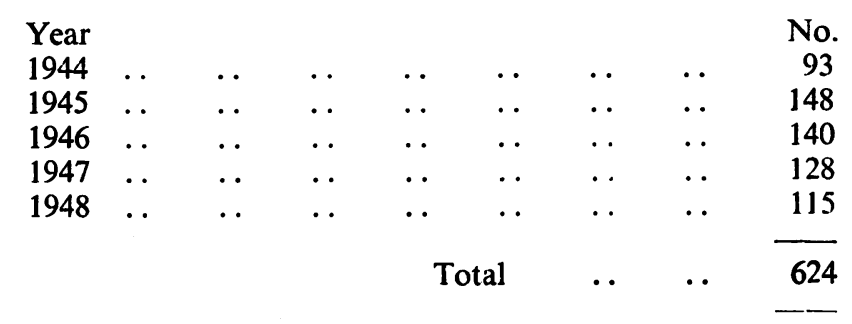

TABLE II

Classification by Diagnosis of Patients Seen

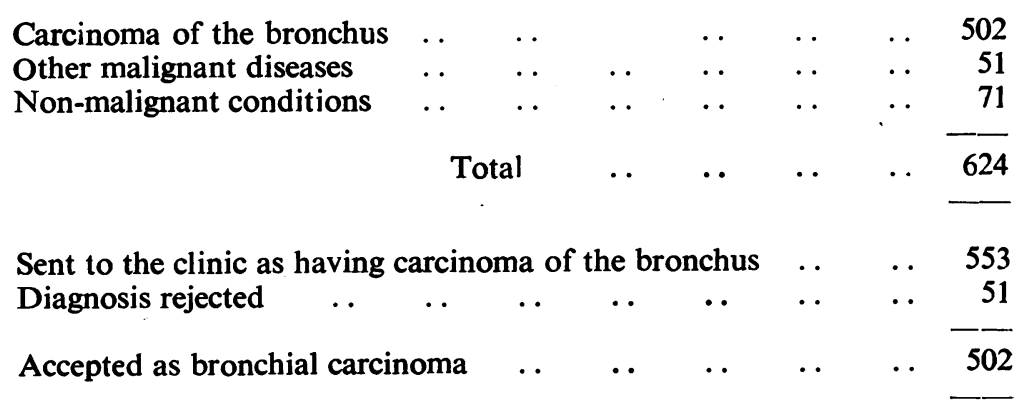


TABLE III

Patients with Malignant Diseases other than Carcinoma of the Bronchus

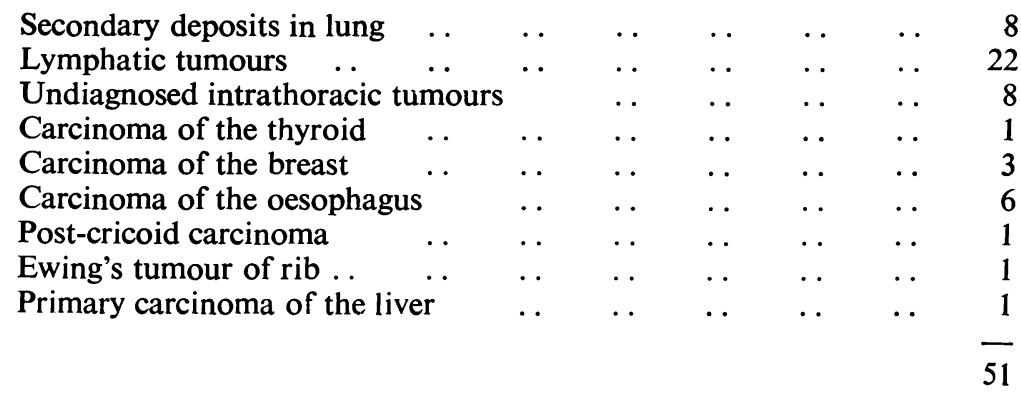

TABLE IV

Patients With Non-malignant Conditions

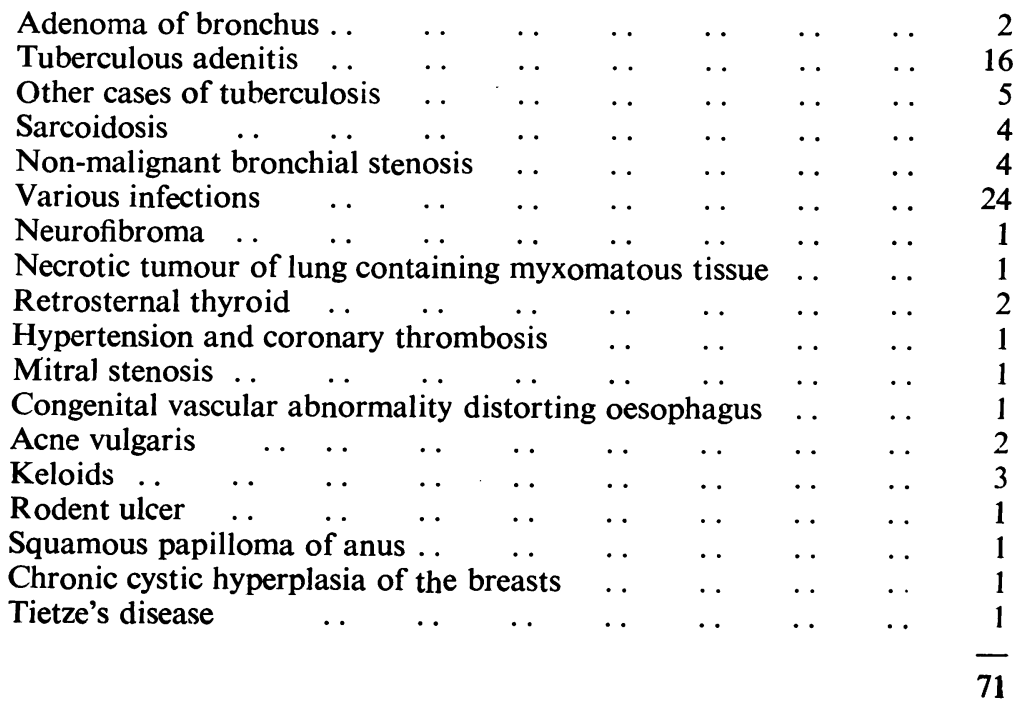

The 122 patients recorded in Tables III and IV include 17 with malignant disease and 34 with non-malignant disease sent to the clinic because they were thought to be suffering from carcinoma of the bronchus, and 71 with other diseases (34 malignant, 37 non-malignant) sent for special investigation or treatment which the clinic could arrange. Only the first group of 51 is of interest to this report, and the diagnoses made in these cases are set out in Table V.

It can be seen that the total number of patients sent to the clinic as suffering from carcinoma of the bronchus was 553, in whom the diagnosis was accepted in 502 and rejected in 51, being replaced by a diagnosis of some other malignant disease in 17 cases and of some non-malignant condition in 34. Hereafter this report is concerned wholly with the 502 patients accepted after full review as having carcinoma of the bronchus and shown in Table VI. 


\section{TABLE V}

Patients with Rejected Diagnosis of Carcinoma of the Lung

A. Diagnosis of non-malignant condition :

$\begin{array}{lllllllll}\text { Adenoma of the bronchus } & \ldots & \ldots & \ldots & \ldots & \ldots & \ldots & 2\end{array}$

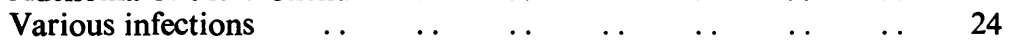

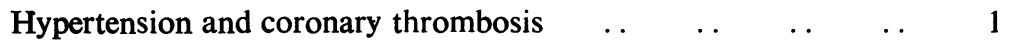

$\begin{array}{lllllllll}\text { Mitral stenosis .. } & \ldots & \ldots & \ldots & \ldots & \ldots & \ldots & \ldots & 1\end{array}$

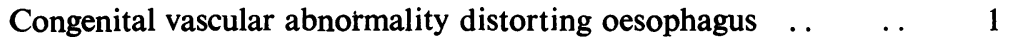

$\begin{array}{llllllll}\text { Myxoma of left upper lobe } & \ldots & \ldots & \ldots & \ldots & \ldots & \ldots & 1\end{array}$

$\begin{array}{llllllll}\text { Non-malignant bronchial stenosis } & \ldots & \ldots & \ldots & \ldots & \ldots & 4\end{array}$

$\begin{array}{r}34 \\ \hline\end{array}$

B. Diagnosis of some other malignant disease :

$\begin{array}{llllllllll}\text { Secondary deposits in lung } & \ldots & \ldots & \ldots & \ldots & \ldots & \ldots & 8\end{array}$

$\begin{array}{lllllll}\text { Undiagnosed intrathoracic tumours } & \ldots & \ldots & \ldots & \ldots & 8\end{array}$

$\begin{array}{lllllllll}\text { Lymphadenoma } & . & \ldots & \ldots & \ldots & \ldots & \ldots & \ldots & 1\end{array}$

TABLE VI

Patients accepted as Having Carcinoma of the Bronchus

A. With histological confirmation :

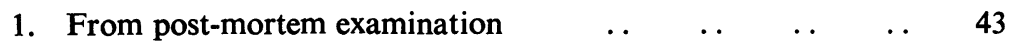

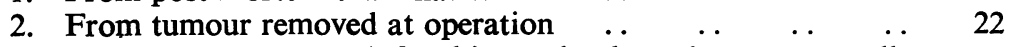

3. From pieces removed for biopsy by bronchoscopy, needle

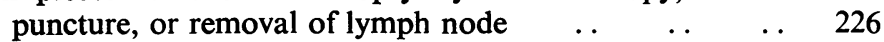

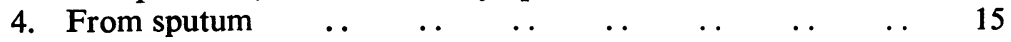

B. Without histological confirmation :

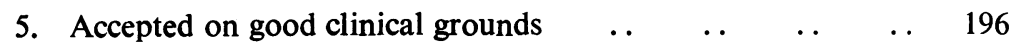

Histological confirmation of the diagnosis was obtained by more than one method in a number of cases. Only one method has been recorded here, preference being given in each case to the order given in Table VI. Positive evidence was obtained from the sputum, for instance, in a number of cases, but in 15 this was the only histological evidence available, and being, in our opinion, the least reliable method it has been placed last. In two cases the patients coughed up a piece of tumour. These are recorded as sputum examinations, though the pieces examined were larger than many biopsy specimens obtained bronchoscopically.

In one case $(A)$ a somewhat guarded pathological report of carcinoma on a specimen removed for biopsy at bronchoscopy was rejected after review. In another $(B)$ histological evidence of squamous-cell carcinoma of the bronchus given in a pathological report on a specimen of sputum was rejected. And in a third case $(C)$ similarly a previous report of undifferentiated-cell carcinoma was rejected and a diagnosis of adenoma was established. 
Case A.-A man of 54 had had a cough and haemoptysis for eight months. Bronchoscopy showed " thickening of mucosa at entrance to right upper lobe bronchus, but good view not obtained."

Pathological report: "Oat-cell carcinoma."

He received no treatment and died 13 months later, post-mortem examination revealing chronic suppurative pneumonia, thrombophlebitis, and brain abscess, but no evidence of tumour.

Case B.-A man aged 65 complained of haemoptysis for three months. Bronchoscopy (September, 1946) showed " the left bronchus below dorsal lobe opening narrowed circularly with mucosa rigid and in tight folds."

Pathological report: "No evidence of malignancy." Histological examination of specimen of sputum (November, 1946) showed " squamous-cell carcinoma of the bronchus."

He was treated with $x$ rays and is still alive three years later. Review of his pathological specimen (sputum) shows no evidence of tumour. The man had bronchitis and had had a coronary thrombosis.

Case C.-A woman aged 61 reported to hospital (March, 1943) complaining of haemoptysis for two weeks. Radiography showed a right hilar opacity, and at bronchoscopy a red ulcerated area was seen below the carina in the right main bronchus. A piece removed showed " fragments of what appears to be an undifferentiated-cell carcinoma."

The patient was not treated, but had occasional attacks of haemoptysis, was otherwise well, and was re-bronchoscoped in August, 1947, when the carina was grossly widened and continuous, on either side, with brilliant red nodular tissue on the medial walls of both main bronchi. A piece removed was reported as adenoma of the bronchus. The patient is still well and working, untreated (October, 1949).

TABLE VII

Sex Distribution of 502 Cases of Bronchial Carcinoma 306 cases with histological confirmation

29 female .. $\quad . \quad$. . . . . $\quad 277$ male

Ratio of $1: 9$

Average age 49.8 years $\quad . \quad$ Average age 54.1 years

196 cases without histological confirmation

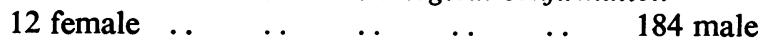

Ratio of $1: 15.3$

Average age 61.0 years $\quad \ldots \quad$ Average age 55.5 years

TOTAL

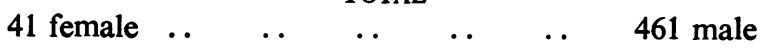

Ratio of $1: 10.7$

Average age 55.4 years $\quad . \quad$ Average age 54.8 years

One other patient, not included in this report, since he was first seen shortly before the clinic was officially established, was accepted as having had a squamous-cell carcinoma, on positive bronchoscopic and histological reports, though review of both now shows clearly that the diagnosis was in error. The patient is still alive and well, over six years after $x$-ray treatment. In the absence of careful review it is possible that cases of this sort are reported as successfully treated from time to time. Since it carries such weight in diagnosis it is, in our opinion, particularly desirable to review and check histological diagnoses made from biopsy specimens. 
The sex and age of the patients seen with carcinoma of the bronchus are set out in Tables VII and VIII. The first symptom of which they complained and their reasons for reporting to their doctors are contained in Tables IX and X.

The duration of symptoms from the onset to the time of first treatment, or till patients were first seen at the clinic if not treated, was recorded. In the 306 patients

TABLE VIII

Age Distribution by Five-year Age-groups

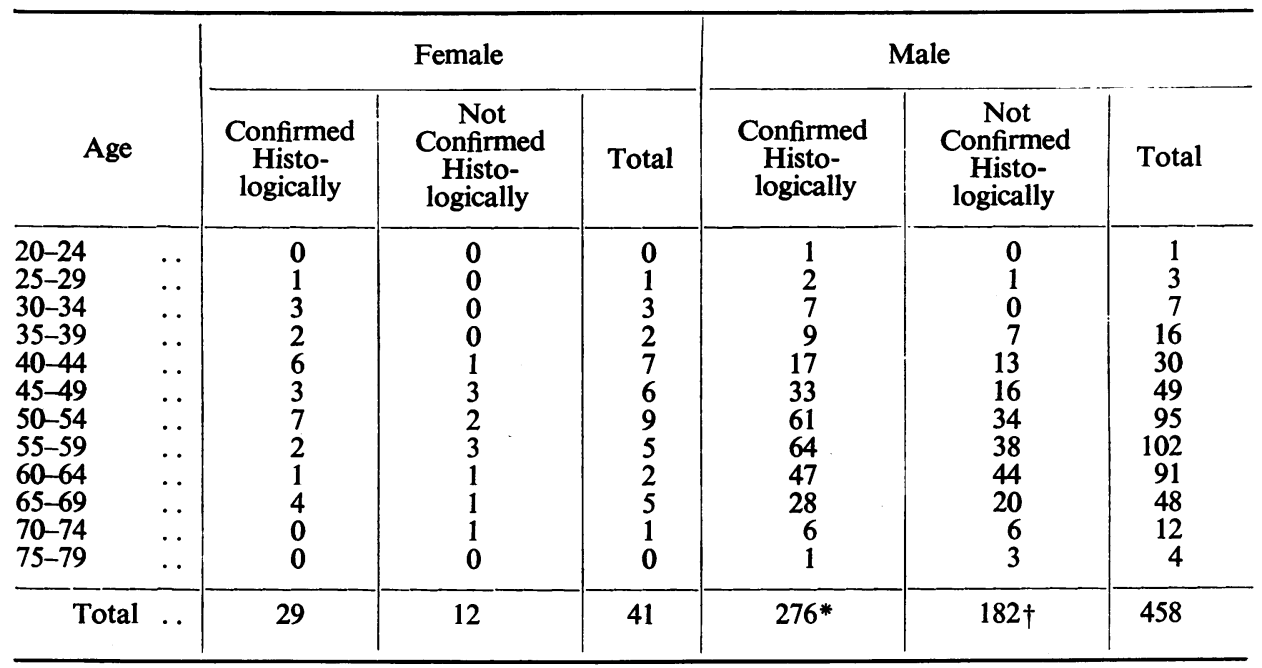

* 1 male age not recorded. +2 males age not recorded.

TABLE IX

FIRST SYMPTOM

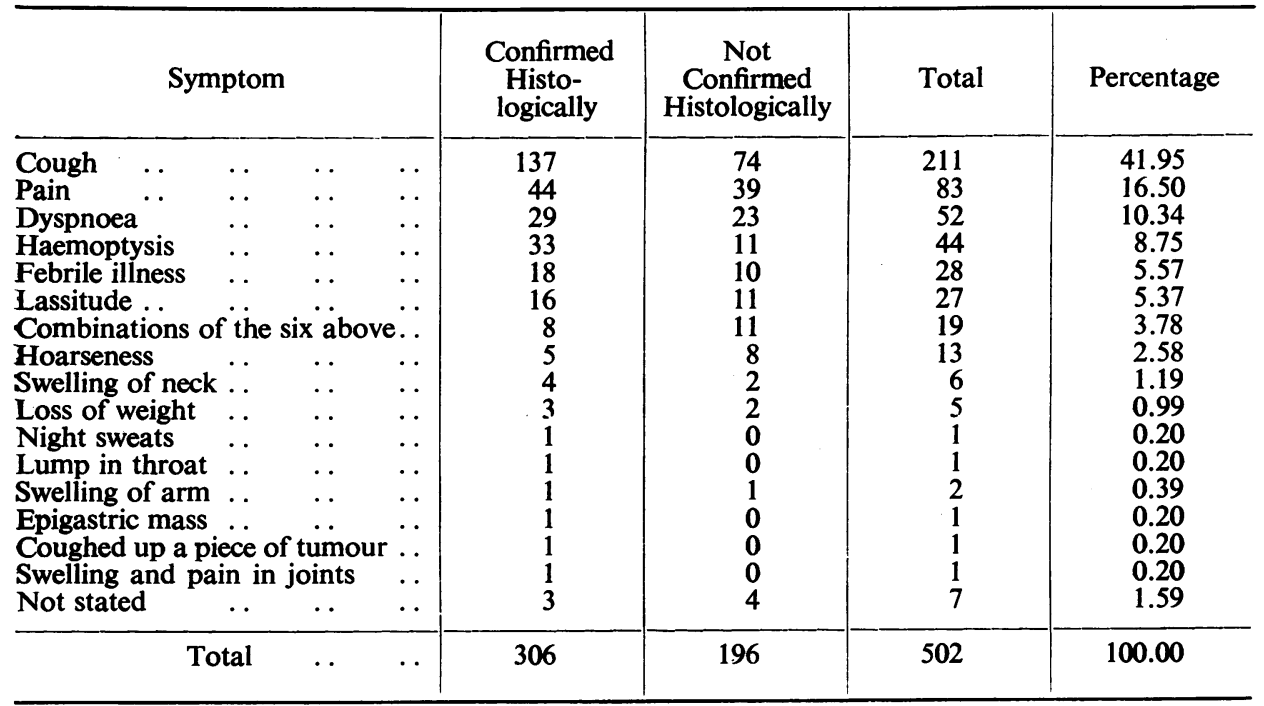


TABLE $X$

First Symptom Causing a Vistr to a Doctor

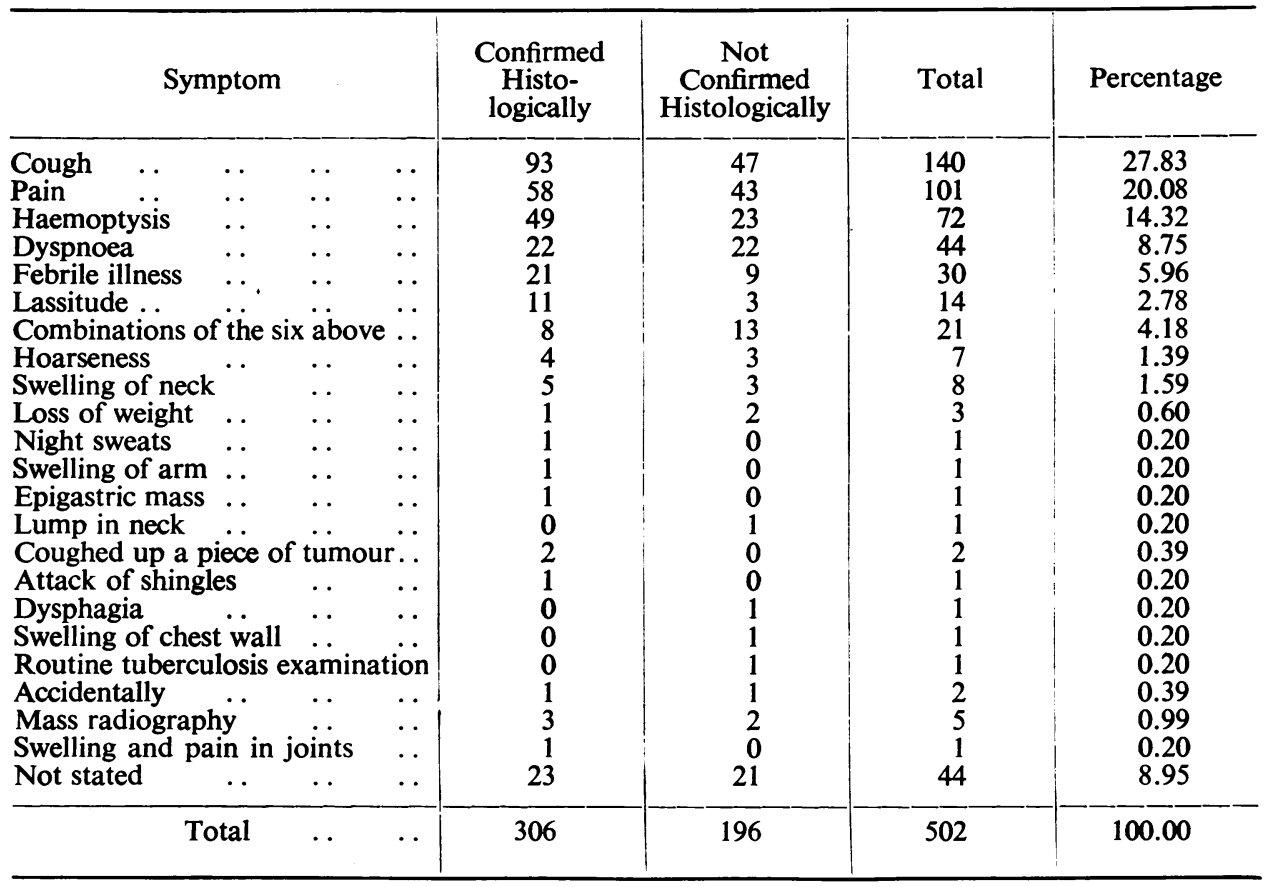

with histological confirmation of the diagnosis, nine were excluded from analysis: in seven because the duration was not stated, and in two because they said they had had symptoms " for years." The average duration of symptoms in the remaining 297 patients was 9.4 months. This includes 13 who stated that they had had symptoms for more than two years (one 10 years, one 6 years, two 5 years, seven 3 years, one 2 years and 6 months, and one 2 years and 4 months). In the 196 patients without histological confirmation of the diagnosis, 17 were excluded from analysis: in five because the duration was not stated, and in 12 because they said they had had symptoms " for years." The average duration of symptoms in the remaining 179 patients was 8.3 months. This includes eight who said that they had had symptoms for more than two years (one 5 years, one 4 years, four 3 years, and two 2 years and 6 months).

In only four cases $(D, E, F, G)$ was there a history of less than one month, the diagnosis being confirmed histologically in each case.

Case D.-A man of 64 with cough for two weeks was not treated and died in nine days.

Case E.-A man of 54 with pain for two weeks was not treated and died in two months.

Case F.-A man of 47 with haemoptysis for two weeks had a full course of $x$-ray therapy and died in 5 months.

Case G.-A man of 38 with cough for two weeks had a full course of $x$-ray therapy and was alive and well one year later (see mass radiography cases). 
The delay from first reporting to a doctor to the time of first treatment or till patients were first seen at the clinic if not treated was also recorded. In 275 patients with histological confirmation the average delay was 6.5 months. The delay was not stated in 32 and was less than one month in 15 . In 172 patients without histological confirmation the average delay was 6.2 months. The delay was not stated in 24 and was less than one month in seven. On an average patients waited from two to three months before reporting their symptoms to a doctor, and it was then six months more before they reached the clinic or started treatment.

In three patients $(G, H, I)$ with histological confirmation of the diagnosis the reason for first reporting to a doctor was on advice given at a mass radiography unit. In two cases $(J, K)$ without histological confirmation similar reference from a mass radiography unit occurred.

Case G.-A man of 38 was symptom-free when a radiograph was taken but did not reach the clinic for four months, by which time he had had a cough for two weeks. He was treated with $x$ rays and was alive and well one year later (see cases with history of less than one month).

Case H.-A man of 63 had had a cough for seven months. It was three months after mass radiography before he reached the clinic. He was treated with $x$ rays and was alive and well one year later.

Case I.-A man of 55 was symptom-free when a radiograph was taken but did not reach the clinic for five months, by which time he had had dyspnoea and pain for one month

TABLE XI

Location of Primary TUMours

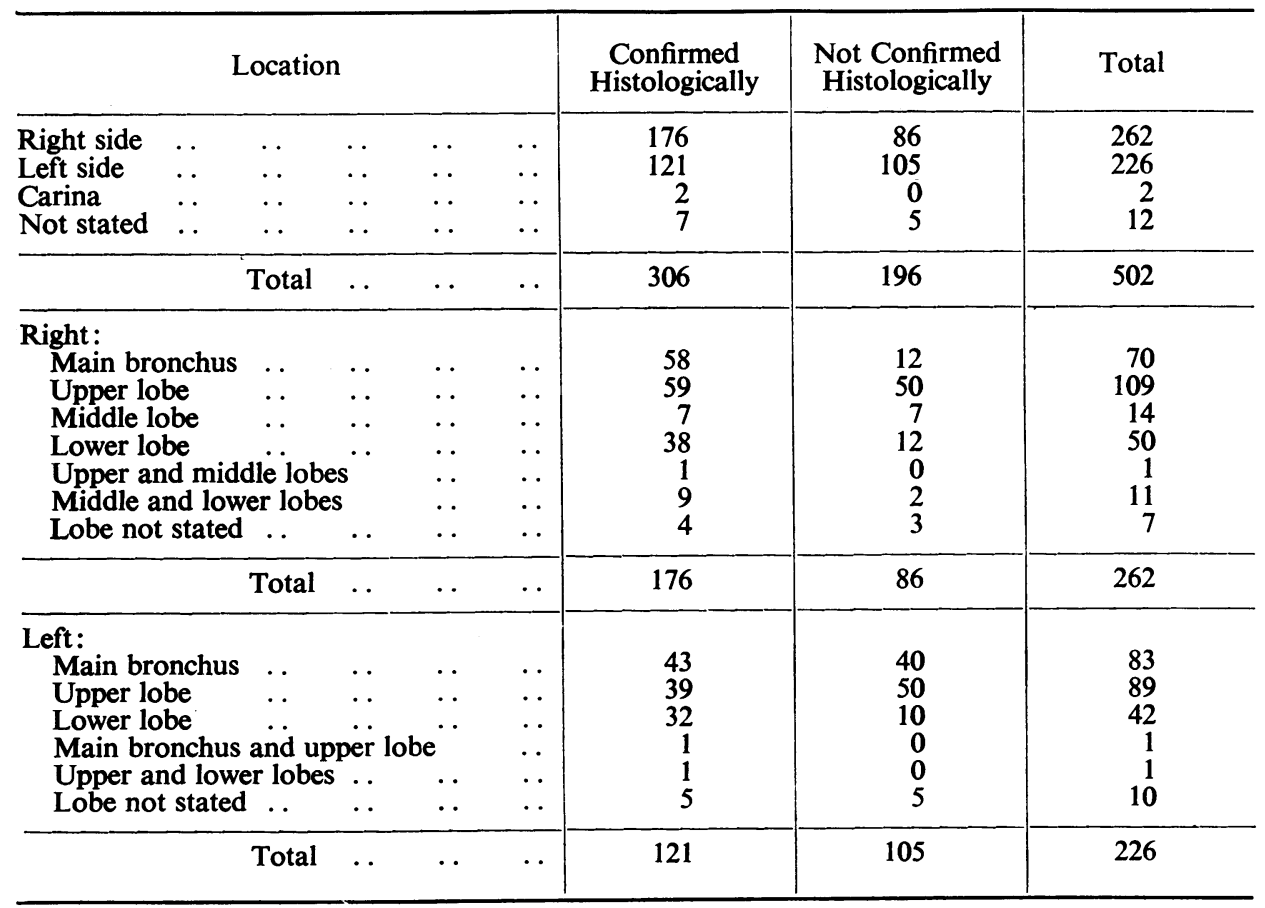


and was found to have developed a pleural effusion. He was not treated and died in six months.

Case J.-A man of 58 had been complaining of cough and lassitude for three months before a radiograph was taken, and reached the clinic one month later. He received a palliative course of $x$-ray therapy and died in two months.

Case K.-A man of 52, who had been complaining of lassitude for nine months, had had a radiograph taken five months before he reached the clinic. He had a palliative course of $x$-ray therapy and died in five months.

The positions of the primary tumours in this series are set out in Table XI.

There were two patients $(L, M)$ with tumours of the carina involving both main bronchi.

Case L.-A man of 55, who had had a cough for two months, went for treatment nearer his home and died in six months.

Case M.-A woman of 32, who had had haemoptysis for 19 months, was found to have a rounded shadow in the chest, thought to be a dermoid cyst. At operation the shadow was found to be that of an enlarged lymph node due to Hodgkin's disease. The anaesthetist saw a carcinoma on the carina: a specimen was removed for biopsy and was reported as adenocarcinoma. The patient had a full course of $x$-ray therapy and died in nine months.

The reports on the 306 patients in whom the diagnosis was confirmed histologically are listed in Table XII.

\section{TABLE XII}

\begin{tabular}{|c|c|c|c|c|c|c|c|c|}
\hline PATHOLOGical REPORTS ON 306 & $\begin{array}{r}\text { Cases } \\
\text { DIAG }\end{array}$ & $\begin{array}{l}\text { WITH } \\
\text { GNOSIS }\end{array}$ & Hist & LOGICA & & CONFIRI & ATION & OF \\
\hline Squamous-cell carcinoma & $\ldots$ & . & . & . & .. & . & 135 & \\
\hline Well-differentiated squamous- & -cell ca & rcinome & & . . & . & . & $5\}$ & 148 \\
\hline Anaplastic squamous-cell carc & cinoma & & . & . & . & . & 8) & \\
\hline Oat-cell carcinoma $\quad .$. & .. & . & . & .. & . & .. & 58 & \\
\hline Carcinoma & .. & .. & .. & .. & .. & .. & 24 & \\
\hline Columnar-cell carcinoma & .. & $\ldots$ & .. & . & . & . & 23 & \\
\hline Adenocarcinoma $\quad .$. & .. & . & .. & . & . & . & 17 & \\
\hline Undifferentiated carcinoma & .. & . & .. & $\ldots$ & . & . & 14 & \\
\hline Anaplastic carcinoma .. & .. & .. & $\ldots$ & $\ldots$ & $\ldots$ & $\ldots$ & 9 & \\
\hline Pleomorphic-cell carcinoma & .. & . & . & . & . & . & 4 & \\
\hline Degenerate neoplastic cells & .. & .. & .. & .. & .. & . & 2 & \\
\hline Transitional-cell carcinoma & .. & . & . & $\ldots$ & $\ldots$ & $\ldots$ & 1 & \\
\hline Prickle-cell carcinoma & .. & . & .. & $\ldots$ & . & . & 1 & \\
\hline Spheroidal-cell carcinoma & & . & .. & . & $\ldots$ & . & 1 & \\
\hline Anaplastic and oat-cell carcin & noma & & .. & $\ldots$ & .. & . & 1 & \\
\hline Adenocarcinoma and squamo & us-cell & carcino & oma & $\ldots$ & .. & $\ldots$ & 1 & \\
\hline Polyhedral-cell carcinoma & .. & .. & .. & . & .. & .. & 1 & \\
\hline Tumour fragments & . & .. & .. & . & .. & . & 1 & \\
\hline & & & tal & . & 。 & $\cdots$ & 306 & \\
\hline
\end{tabular}

A number of these patients with bronchial carcinoma were also found to be suffering from some other abnormality: several had old tuberculous lesions, one had coarctation of the aorta, one a para-oesophageal hernia, one a calcified hydatid cyst in the liver, and one sarcoidosis and senile dementia. Five patients had, or had had, 
TABLE XIII

METHODS OF TREATMENT EMPLOYED

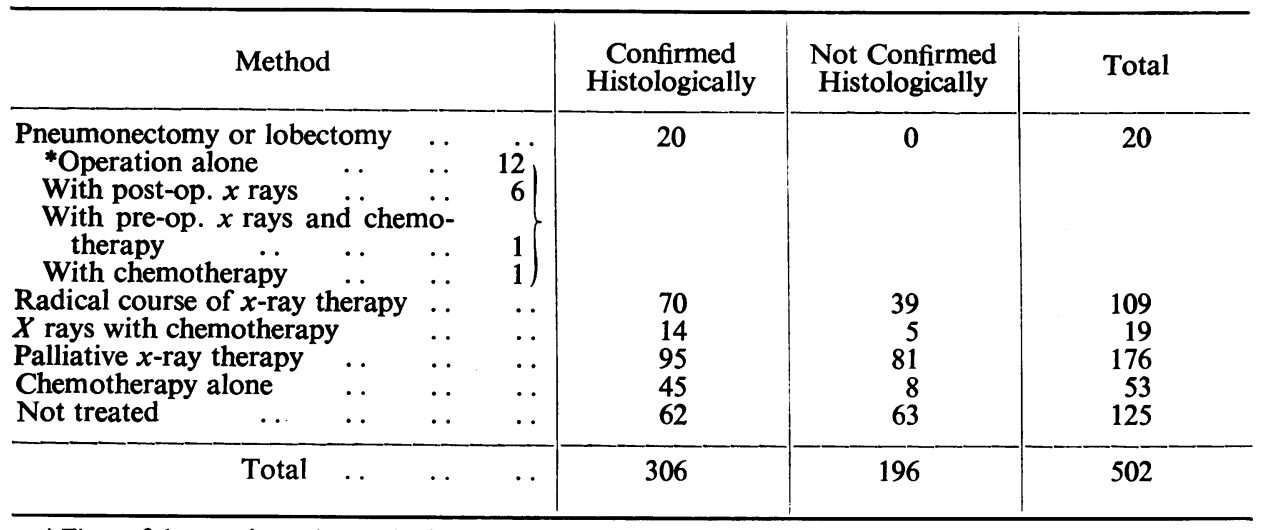

* Three of these patients also received palliative $x$-ray therapy for relief of symptoms due to recurrence shortly before death.

other malignant tumours, one (Case $M$ ) had Hodgkin's disease, one had a squamouscell carcinoma of the pinna, one had had a carcinoma of the larynx treated three years before, one a sarcoma of the femur treated 15 years before, and one a carcinoma of the rectum treated 17 years before.

Twenty-one of the patients with histological confirmation of the diagnosis and 12 without had a thoracotomy and were regarded as inoperable. In 20 (one after radical $x$-ray therapy) thoracotomy was performed and the surgeon proceeded to the removal of the tumour. Radical $x$-ray treatment was given to 147 patients $(29 \%)$, including 18 with combined $x$-ray therapy and chemotherapy given experimentally. Palliative treatment for relief of symptoms only or no treatment at all was given to 355 patients $(71 \%)$.

The distinction between palliative and radical $x$-ray therapy is quite clear in most cases, but there is a border-line group where treatment has been persisted in despite advanced disease owing to marked improvement in general condition. When in doubt these have been called radical treatments, and some have had a tumour dose as low as 4,000 $\mathrm{r}$ in five or six weeks. In a few cases planned radical treatment had to be abandoned, and these have been counted as palliative only if a tumour dose of 4,000 $r$ had not been exceeded. The moderate tumour dose of 4,000 $\mathrm{r}$ has been arbitrarily chosen, as it provides a bias in selection in favour of radical treatment and forms a convenient dividing line between the few cases where classification into radical and palliative treatment is in doubt.

The results of treatment as judged by survival are set out in the following Tables. Table XIV shows the small group of patients treated surgically.

Of the 306 patients with histological confirmation of the diagnosis, 96 lived for one year or more (Table XV), 21 of them being still alive at the last follow-up check (Table XVI).

The results of treatment of the $\mathbf{3 0 6}$ patients with histological confirmation of the diagnosis are shown also in Table XVII and of the group without histological confirmation in Table XVIII. 


\section{TABLE XIV}

Operation only : 12

\section{Results of Surgical Treatment}

1 lobectomy alive at 19 months

4 pneumonectomies alive at $39,36,23,23$ months

7 pneumonectomies died at $35, * 33,25, * 24, * 4,3$, and 2 months

Operation and post-operative $x$-ray therapy : 5

1 lobectomy died at 10 months

1 pneumonectomy alive at 22 months

3 pneumonectomies died at 13,12 , and 4 months

Pre-operative $x$-ray therapy and chemotherapy and pneumonectomy : 1

1 pneumonectomy alive at 7 months

Operation and chemotherapy : 1

1 pneumonectomy died at 9 months

* These 3 patients also received palliative $x$-ray therapy for recurrence shortly before their deaths.

TABLE XV

Survival Time of ONe or More Years in 306 Patients with Histological Confirmation OF DIAGNOSIS

\begin{tabular}{|c|c|c|c|c|c|c|}
\hline \multirow{2}{*}{\multicolumn{4}{|c|}{ Treated by }} & \multicolumn{3}{|c|}{ Died or Still Living at } \\
\hline & & & & 1-2 Years & 2-3 Years & 3 Years or More \\
\hline $\begin{array}{l}X \text {-ray therapy } \\
\text { Operation ... } \quad . \\
\text { Chemotherapy } \ldots \\
X \text { rays and chemotherapy } \\
\text { Operation and } x \text { rays } \\
\text { Not treated } \quad . .\end{array}$ & $\begin{array}{l}\cdots \\
\cdots \\
\cdots \\
\cdots\end{array}$ & $\begin{array}{l}\cdots \\
\cdots \\
\cdots \\
\cdots \\
\cdots\end{array}$ & $\begin{array}{l} \\
\therefore \\
\therefore \\
\because \\
\cdots \\
\therefore\end{array}$ & $\begin{array}{r}45 \\
9 \\
5 \\
6 \\
3 \\
3\end{array}$ & $\begin{array}{r}12 \\
5 \\
0 \\
2 \\
0 \\
0\end{array}$ & $\begin{array}{l}4 \\
2 \\
0 \\
0 \\
0 \\
0\end{array}$ \\
\hline Total & .. & .. & .. & 71 & 19 & 6 \\
\hline
\end{tabular}

TABLE XVI

Survival Timfs of ONe Year or More of 21 out of 306 Patients with Histolological ConfiRmation of the Diagnosis

11 were living following $x$-ray therapy at

5 were living following operation at ..

2 were living following chemotherapy at

2 were living following chemotherapy and $x$ rays at

1 was living following operation and
$60, * 39,36,30,27,25,25,21$,

20,17 , and 17 months

$39,36,23,23$, and 19 months

21 and 14 months

30 and 27 months

22 months

* This patient had a large, rapidly growing tumour about which there has been some argument among the pathologists. It has been called an oat-cell carcinoma, a haemangio-endothelioma, and an anaplastic carcinoma. It has also been called a granuloma. After review of both the clinical and pathological evidence, we have accepted this as an anaplastic carcinoma, the pathologists to both hospitals concurring.

The results in the whole group (with and without histological confirmation of the diagnosis, treated and untreated) are given in Table XX. All patients lost sight of have been counted as having died of cancer in the first year. This amounts to 19 patients lost sight of (11 not treated, four palliative $x$-ray therapy, three chemotherapy, 
TABLE XVII

Survival Time of 98 out of 306 Patients with 'Histological Confirmation of the DiAGNOSIS

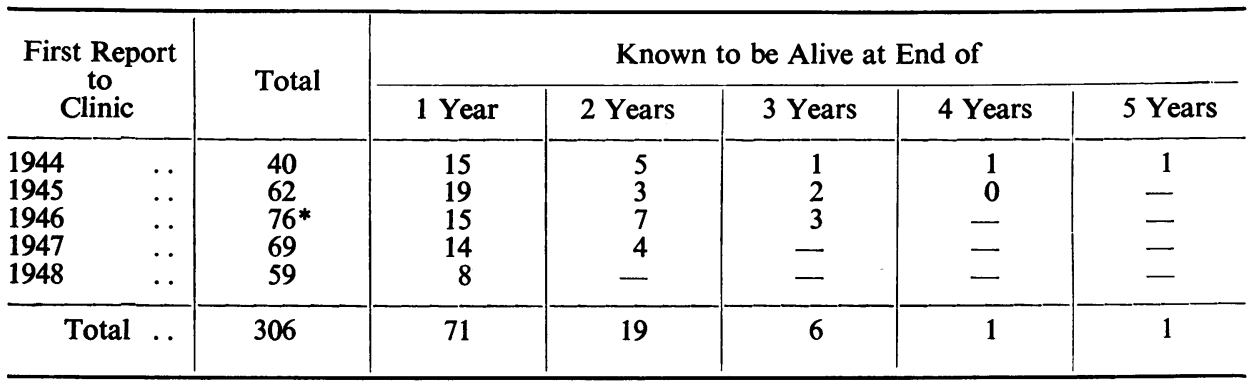

* One patient, seen at the clinic for the first time in 1946, died shortly afterwards, but he had attended previously 7 years before, when a piece removed for biopsy had shown a squamous-cell carcinoma. No treatment had been given.

\section{TABLE XVIII}

Survival Time of Eight out of 196 Patients without Histological Confirmation OF THE Diagnosis

6 were living following $x$-ray therapy at $37,26,24,21,13$, and 13 months 2 were living, having had no treatment, at 21 and 16 months

TABLE XIX

Survival Time of One Year or More of Patients Still Alive at last Review With AND WITHOUT Histological CONFIRMATION

\begin{tabular}{|c|c|c|c|c|c|}
\hline \multirow{2}{*}{ Following Treatment } & & \multicolumn{4}{|c|}{ More than } \\
\hline & & 1 Year & 2 Years & 3 Years & 4 Years \\
\hline $\begin{array}{lll}X \text {-ray therapy } & \ldots & \ldots \\
\text { Operation } & \ldots & \ldots \\
\text { Chemotherapy and } & x \text { rays } \\
\text { Chemotherapy } & \ldots & \ldots \\
\text { Operation and } x \text { rays } & \ldots \\
\text { Without treatment } & \ldots\end{array}$ & $\begin{array}{l}\cdots \\
\cdots \\
\cdots \\
\cdots \\
\cdots\end{array}$ & $\begin{array}{r}17 \\
5 \\
2 \\
2 \\
1 \\
2\end{array}$ & $\begin{array}{l}9 \\
2 \\
2 \\
0 \\
0 \\
0\end{array}$ & $\begin{array}{l}3 \\
1 \\
0 \\
0 \\
0 \\
0\end{array}$ & $\begin{array}{l}1 \\
0 \\
0 \\
0 \\
0\end{array}$ \\
\hline Total & . & 29 & 13 & 4 & 1 \\
\hline
\end{tabular}

one radical $x$-ray therapy) out of 502 ( $96 \%$ follow-up). No patient has been counted as dying of intercurrent disease. All patients have been counted whether previously treated (2) or not, or whether treated by us or treated elsewhere (22); only one of those treated elsewhere is alive over one year from treatment, and this patient had part of his treatment at the Royal Cancer Hospital and part at St. Luke's Hospital, Guildford.

Seventy-five patients have been treated with chemotherapy. Of these 54 had advanced disease and were treated with chemotherapy alone (seven with urethane, four with dienoestrol, and 43 with chlorethylamine). One patient was treated with chlorethylamine post-operatively and lived nine months. Twenty patients were treated by chemotherapy and $x$-ray therapy combined. (One of these subsequently had a pneumonectomy performed and was alive seven months later; two others were still alive at the last follow-up 30 and 27 months after treatment.) 
TABLE XX

Combined Table of Results of 306 Patients with Histological Confirmation and 196 ACCEPTED Clinically

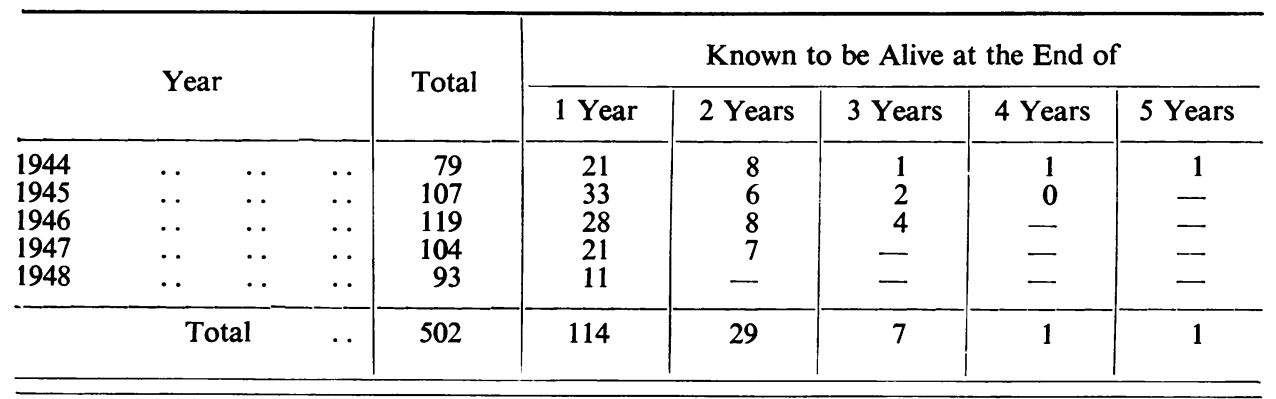

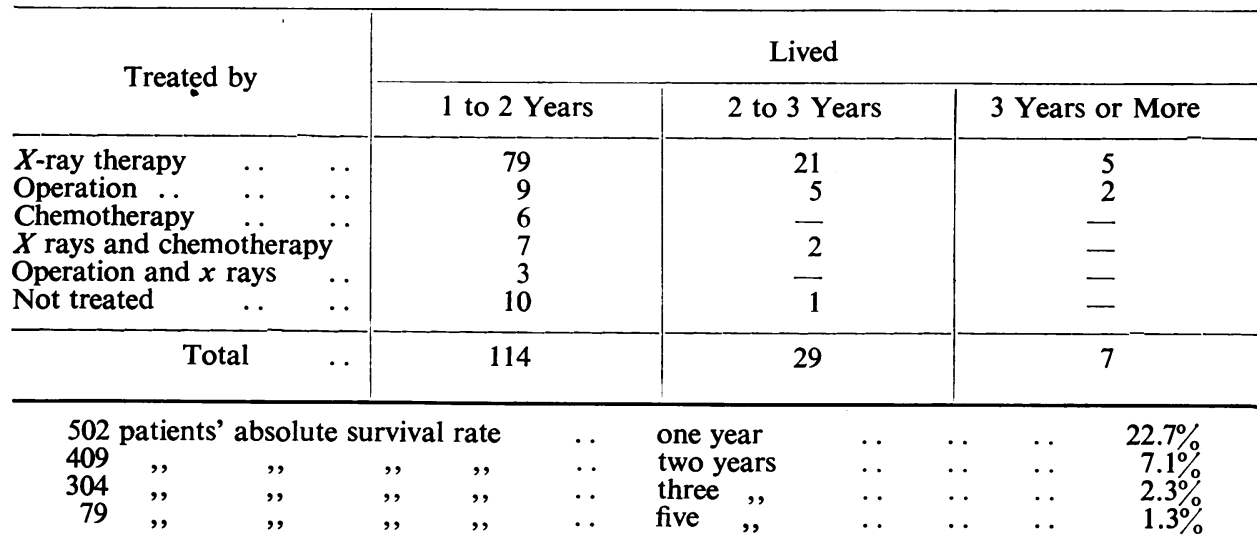

Of the 54 patients treated with chemotherapy alone, one was still alive at the last follow-up 21 months from treatment and another 14 months from treatment. Of the remainder, 49 were known to be dead, and three had been lost sight of. The 49 known to be dead lived an average of 5.4 months after starting treatment. Approximately half the patients treated gained some symptomatic relief, but in many this lasted less than one month. The majority vomited following treatment: one patient vomited repeatedly for 11 days after a single injection $\left(\mathrm{HN}_{2}\right)$ and, by aspiration, collapsed the entire right lung; he has, however, remained alive for 14 months. Three others refused to continue this treatment, but two of these were also having $x$-ray therapy. In a few, symptomatic improvement was striking. One patient, with an oatcell carcinoma and severe superior vena caval obstruction, was very seriously ill, but obtained rapid relief of superior vena caval obstruction after one injection, relapsed, received less benefit from a second, but was well enough for $x$-ray therapy to be given at this stage, and lived nine months. One man with gross hypertrophic pulmonary osteoarthropathy had been attending a rheumatic clinic and complained considerably of joint pains, cough, and haemoptysis; after the first two of four injections $\left(\mathrm{HN}_{2}\right)$ his pains were relieved completely, his haemoptysis ceased, and he gained $12 \mathrm{lb}$. in weight, but there was no visible alteration in the arthropathy. He remained fairly well for six months, his symptoms then returned, and he died three months later. 
One hundred and seventy-six patients received palliative $x$-ray therapy, ranging from a few doses to test radiosensitivity or relieve pain due to a secondary deposit to three to four weeks' treatment to a tumour dose of just under 4,000 $\mathrm{r}$ in the hopes both of relieving symptoms and prolonging life. One was alive when last heard of 21 months after treatment but was suffering from senile dementia; four had been lost sight of; the remaining 171 were known to be dead and had lived an average of 5.6 months after treatment (94 cases with histological confirmation, 5.9 months; 77 cases without, 5.2 months).

Radical $x$-ray treatment (Table XXI) was given to 129 patients. (One hundred and nine received $x$-ray therapy only; $20 x$-ray treatment with chemotherapy, one of whom had a subsequent pneumonectomy and is omitted from the analysis made below.) There are 30 alive, one lost sight of, and 97 dead, who lived an average of 10 months (67 cases with histological confirmation, 9 months; and 30 cases without, 11 months).

Of the four patients who refused thoracotomy (and may have had operable tumours) two are alive and two dead. One lived 22 months and one five months. One patient is alive three years three months after treatment, and the other was alive when last seen nine months after treatment. Five patients were lost sight of, and 12 alive when last seen were not followed up for a full year: all are counted as having died of cancer in the first year. The results presented are, therefore, the worst possible interpretation of the evidence at present available.

TABLE XXI

Results of Treatment By Radical $X$-ray Therapy*

\begin{tabular}{|c|c|c|c|c|c|c|c|c|}
\hline \multirow[b]{2}{*}{ Year } & \multirow[b]{2}{*}{$\begin{array}{c}\text { Number } \\
\text { Seen }\end{array}$} & \multirow{2}{*}{\multicolumn{2}{|c|}{ Radical $X$ rays }} & \multicolumn{5}{|c|}{ Alive at the End of (Years) } \\
\hline & & & & (A) ${ }^{1}$ (B) & $(\mathrm{A})^{2}(\mathrm{~B})$ & (A) ${ }^{3}(\mathrm{~B})$ & $(\mathrm{A})^{4}(\mathrm{~B})$ & (A) ${ }^{5}(\mathrm{~B})$ \\
\hline $\begin{array}{l}1944 \\
1945 \\
1946 \\
1947 \\
1948\end{array}$ & $\begin{array}{r}79 \\
107 \\
119 \\
104 \\
93\end{array}$ & $\begin{array}{l}11 \\
18 \\
20 \\
16 \\
19\end{array}$ & $\begin{array}{r}6 \\
12 \\
11 \\
9 \\
6\end{array}$ & $\begin{array}{rr}8 & 1 \\
8 & 8 \\
10 & 7 \\
6 & 3 \\
3 & 1\end{array}$ & $\begin{array}{cc}2 & 0 \\
1 & 2 \\
5 & 1 \\
4 & 1 \\
- & -\end{array}$ & $\begin{array}{cc}1 & 0 \\
1 & 0 \\
2 & 1 \\
- & - \\
- & -\end{array}$ & $\begin{array}{ll}1 & 0 \\
0 & 0 \\
- & - \\
- & -\end{array}$ & $\begin{array}{l}1= \\
= \pm \\
=-\end{array}$ \\
\hline Total... & 502 & 84 & 44 & $35 \quad 20$ & 12 & 41 & 10 & 0 \\
\hline
\end{tabular}

* Nineteen patients had chemotherapy. $\quad$ +With histological confirmation $=(\mathrm{A})$; without histological confirmation $=(\mathrm{B})$.

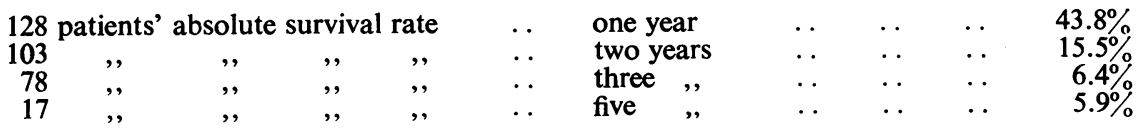

Four patients treated by $x$ rays were found at post-mortem examination to have no evidence of residual tumour at the primary site where they had been irradiated.

Case N.-A man of 47 had a tumour in the left lung which was regarded at thoracotomy as inoperable because of the extension of the growth round the left pulmonary artery, a mass within the arch of the aorta, and nodes along the phrenic nerve and internal mammary artery.

Pathological report: "Undifferentiated carcinoma." The patient lived six months after $x$-ray therapy. At post-mortem examination the collapsed left lung contained no residual neoplasm recognizable macroscopically, and only a few carcinoma cells lying 
singly or in small groups in dense fibrous tissue microscopically. Metastases were found in lumbar vertebral bodies, the shaft of the right femur, both adrenals, the right and left supraclavicular nodes, and the right lung of mainly anaplastic large polyhedral-cell carcinoma.

Case O.-A man aged 26 was found at thoracotomy to have direct extension of the tumour from the left lung into the mediastinum.

Pathological report: "Oat-cell carcinoma."

The patient lived eight months following $x$-ray therapy. At post-mortem examination a healed carcinoma of the left lung was found with no residual tumour cells. Secondary oat-cell carcinoma was present in the left supraclavicular lymph nodes, pancreas, small intestine, brain, and kidney.

Case P.-A man of 53, before being seen at the clinic, had been treated with $x$ rays for a bronchial carcinoma in the right lung. This treatment had been given at the Christie Hospital and Holt Radium Institute, Manchester. He lived tour months following $x$-ray treatment and chemotherapy, at the Royal Cancer Hospital, for recurrence. At postmortem examination metastases of bronchogenic anaplastic oat-cell carcinoma were found in the pineal, cerebrum, parotid salivary gland, and adrenals, but no residual tumour was detected in the right lung.

Case Q.-A man of 68 had stenosis of the left lower lobe bronchus.

Pathological report: "Squamous-cell carcinoma extensively infiltrating the mucous and submucous layers."

He was in poor general condition and unfit for operation. He died two months after $x$-ray therapy, post-mortem examination showing coronary thrombosis, haemo-pericardium, bilateral pleural effusion, and tuberculosis, but no definite evidence of residual tumour or metastases. This examination was not, however, carried out in either of the two hospitals and does not appear from the report obtained to have been complete.

\section{ConCLusions}

In our opinion the work of the clinic has been valuable, first as a means of collecting information about patients with carcinoma of the bronchus regarding their early symptoms, the delay in reaching hospital, the age and sex distributions, and particularly the sex ratio in a group where diagnosis is rigorously checked. It has also made apparent errors in diagnosis that may be made even in a specialist unit, and how apparently successful treatment of patients suspected of having had bronchial carcinoma needs careful review. Facts regarding occupation, place of residence, and the smoking habit have also been collected but have not yet been analysed. The chief handicap in this part of the work is that we have had access to only a selected portion of the material, and that the records and follow-up of the remainder are not yet entirely satisfactory.

We think that the clinic has also been of value as a means of assessing non-surgical methods of treatment for these patients. Since some 9,000 persons are dying of carcinoma of the bronchus in England and Wales each year and probably fewer than 200 have a pneumonectomy performed, this would seem to be of importance, especially since it is unrealistic to believe that diagnosis will be made at a much earlier stage in a greatly increased proportion of these patients in the near future.

With regard to chemotherapy, we have in the few patients treated seen no benefit from urethane or dienoestrol. The improvement noted in a number of patients treated with the chlorethylamines* has been transient and, with one possible

* The chlorethylamines used have been: methyl bis-2-chlorethylamine $\left(\mathrm{HN}_{2}\right)$; dimethylchlorethylamine $\left(\mathrm{CLE}_{3}\right)$; and $\mathrm{N}: \mathrm{N}$ di-(2-chlorethyl)-1-naphthylamine $\left(\mathrm{R}_{\mathbf{4 8}}\right)$. 
exception-and this may well have been independent of the treatment-we have thought that the discomfort caused by the treatment far outweighed the slight temporary benefit obtained. Many patients had the discomfort without the benefit. The temporary improvement suggested that some relief of toxic symptoms attributable to sepsis might have occurred. In some there was improved appetite, gain in weight, diminution in cough, sputum, haemoptysis, and pain, with a rise in haemoglobin in a few. One patient-later found to have a bronchial adenoma which was successfully treated by pneumonectomy-had rapid relief of a toxaemic episode with marked general improvement and gain in weight following injections of chlorethylamine.

The palliative value of $x$-ray therapy has been most marked. In fact, it holds out the only regular means of symptomatic relief in the majority of patients with this disease who come to hospital. Relief of haemoptysis is almost constant, though it occasionally returns. Cough is nearly always lessened and sometimes relieved. Relief of dyspnoea is much more variable, but when it does occur may be dramatic. Relief of superior vena caval obstruction is one of the most useful effects of palliative irradiation. Pain from secondary deposits in bone is frequently relieved, but pain in the chest, particularly when due to the direct extension to the pleura and bone, is much less constantly benefited and some cases do not seem to respond at all. Patients with pleural effusion seem to derive no benefit. Those whose general condition is really poor usually derive no more than temporary relief and this is seldom worth the effort expended by the patient or the department. Some patients feel-and are-a good deal worse as a result of the treatment given, especially if infection is a marked feature. The concurrent use of penicillin and other means may get over this difficulty and, if the treatment opens up the bronchus, sepsis may then be further relieved by drainage.

Attempts at curative treatment have proved interesting. The results have purposely been presented in their worst light, but it is clear that prolongation of life can sometimes be obtained even in a group of patients with advanced disease from which nearly all the operable cases have been excluded. It is also clear that the primary tumour can sometimes be made to disappear, as four necropsies and one operation mentioned early in the report show. A careful follow-up of the 30 patients still alive following $x$-ray therapy will be continued.

\section{SUMMARY}

A report of the first five years' work of the Joint Consultation Clinic for Neoplastic Diseases established by the Brompton Hospital and the Royal Cancer Hospital is presented. From the total number of patients seen, the case-records of 502, in whom the diagnosis of carcinoma of the bronchus was accepted, are analysed according to sex, age, first symptom, reason for reporting to a doctor, site of tumour, method of treatment, and result obtained.

We wish to thank Dr. D. A. Galton, who has carried out most of the chemotherapy trials, taking over the work started by Dr. O. H. Warwick and continued by Dr. J. Watkinson; he has also helped in the compilation of that section of this report. We are greatly indebted to Miss J. C. Hatch, who has acted as secretary to the clinic and conducted the follow-up since August, 1947, and has done a great deal of the work required to produce this report. 